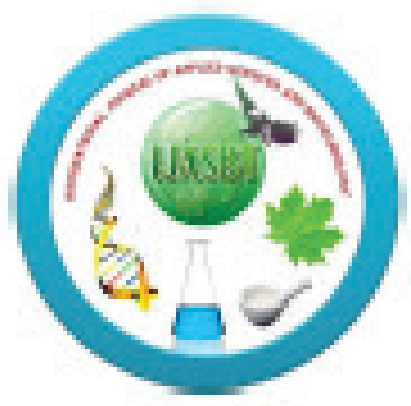

Avallable online at wwwijastetorg

International Journal of Applied Sciences and Biotechnology A Rapid Publishing Journal

\begin{tabular}{|c|c|c|}
\hline \multicolumn{2}{|c|}{ APPUED SCENCES } & BIOHECYNELGSY \\
\hline $\begin{array}{l}\text { Biochemistry } \\
\text { Molecular biology } \\
\text { Milcrobiology } \\
\text { Cell biology }\end{array}$ & $\begin{array}{l}\text { Immunobiology } \\
\text { Biolnformatics } \\
\text { Nowel drug delivery rystem } \\
\text { Pharmacology }\end{array}$ & $\begin{array}{l}\text { Microblal biotechnolosy } \\
\text { Medical biotechnology } \\
\text { Industril blotechnology } \\
\text { Environmental blotechnolosy }\end{array}$ \\
\hline $\begin{array}{l}\text { Cytology } \\
\text { Genetics } \\
\text { Patholosy }\end{array}$ & $\begin{array}{l}\text { Neurablology } \\
\text { Bio-physics } \\
\text { Botany }\end{array}$ & Nanotechnology \\
\hline $\begin{array}{l}\text { Medicinal chemistry } \\
\text { Polymer sdences } \\
\text { Analytical chemistry } \\
\text { Natural chemistry }\end{array}$ & $\begin{array}{l}\text { Zoology } \\
\text { Allied science } \\
\text { Esth sdence }\end{array}$ & \\
\hline
\end{tabular}

If any queries or feedback, then don't hesitate to mail us at: editor.ijasbt@gmail.com 


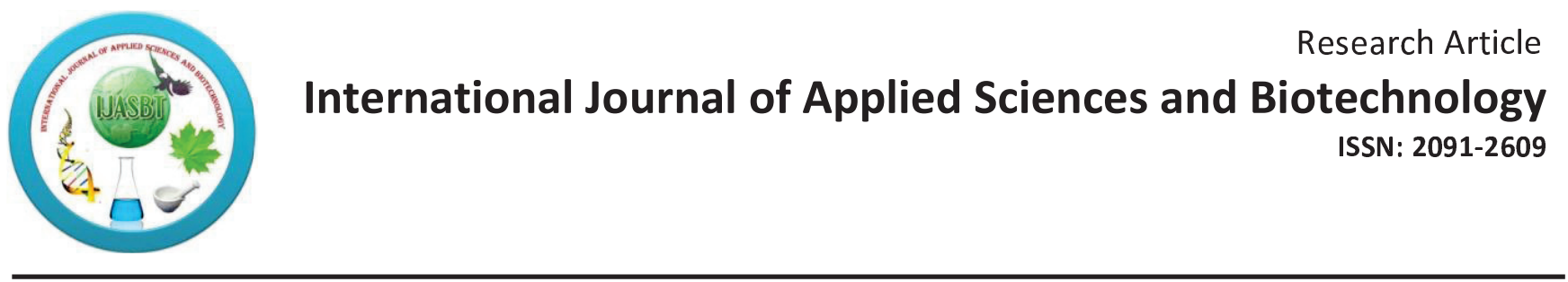

\title{
CITRIC ACID PRODUCTION BY WILD AND UV - TREATED STRAINS OF ASPERGILLUS NIGER ON TWO DIFFERENT MINERAL SALT MEDIA
}

\author{
Valentine E. Anyanwu ${ }^{1 *}$ and Phillip O. Okerentugba ${ }^{2}$ \\ ${ }^{1 *}$ Department of Microbiology, Federal University of Technology, P.M.B. 1526, Owerri, Imo State, Nigeria. \\ ${ }^{2}$ Department of Microbiology, University of Port Harcourt, P.M.B. 5323, Port Harcourt, Rivers State, Nigeria. \\ *Corresponding Author: Email: anyanwuve@yahoo.com, Phone: +2348030469256
}

\begin{abstract}
Microbial production of citric acid by a novel Aspergillus niger EE-12 and its UV - treated strain (UV-1) were carried out in shake flask cultures using mineral salt media containing sucrose or fructose as the carbon and energy sources. The highest citric acid concentration $(36.1 \pm 0.1 \mathrm{~g} / \mathrm{l})$ was obtained with the UV - treated strain UV-1 after 144 hours in medium containing sucrose and this was significantly higher $(\mathrm{p}<0.05)$ than the concentration produced by its parent strain EE-12. Citric acid production using medium containing sucrose (Sucrose salt medium) was significantly higher $(\mathrm{p}<0.05)$ than from medium containing fructose (Fructose salt medium) for both organisms. Product and growth yield coefficients $\left(Y_{\mathrm{CA} / \mathrm{S}}, \mathrm{Y}_{\mathrm{CA} / \mathrm{F}}, \mathrm{Y}_{\mathrm{CA} / \mathrm{X}}, \mathrm{Y}_{\mathrm{X} / \mathrm{S}}, \mathrm{Y}_{\mathrm{X} / \mathrm{F}}\right)$ and volumetric rates $\left(\mathrm{Q}_{\mathrm{F}}, \mathrm{Q}_{\mathrm{S}}\right.$, $\mathrm{Q}_{\mathrm{CA}}, \mathrm{Q}_{\mathrm{X}}$ ) were studied and compared for each of the test organisms based on the media (sucrose and fructose salt media) using students t-test analysis. This research indicated that the fungi strains are efficient for citric acid production using sucrose based medium.
\end{abstract}

Key words: Citric acid production, Aspergillus niger, sucrose, improved UV-1 strain, kinetic parameters.

\section{Introduction}

Fermentation processes play a major role in the production of most organic acids. Different microorganisms have been exploited to convert carbohydrates to high yields of organic acids. This property is demonstrated by various filamentous fungi, yeast and bacteria (Yalcin et al., 2010). Fungal fermentation acids produced commercially, or at least studied extensively include citric, fumaric, gluconic, itaconic, kojic and gibberellic acids (Casida, 1968; Magnuson and Lasure, 2004). Except for the production of citric acid which is entirely by fungal fermentation, there is frequently great competition between microbiological and chemical processes for production of the various organic acids (Crueger and Crueger, 1984; Magnuson and Lasure, 2004).

Citric acid occurs naturally as a component of many fruits (Papagianni, 2007). Around $70 \%$ of the citric acid produced is used in the food and beverage industry, approximately $12 \%$ in pharmaceuticals and about $18 \%$ in other industrial utilizations (Kapoor et al., 2004; Yigitoglu, 1992). It is widely used in the food industry as an acidulant and flavouring agent in beverages, confectionery and other foods, and in leavening systems for baked goods because of its high solubility, extremely low toxicity, and a pleasant sour taste (Kapoor et al., 2004). As a food constituent, its use is unrestricted because it has generally regarded as safe (GRAS) status (Waites et al., 2001; Jamal et al., 2005). Citric acid is used in maintaining metals in solution for electroplating, as a cleaning and 'pickling' agent for metals. It is employed commercially as a chelating and sequestering agent and as plasticizers (Alben and Erkmen, 2004). Recently, because of its easy biodegradability, this organic acid has also found a ready acceptance in the detergent industry in place of polyphosphates and in the removal of sulphur in stack gases, a process applicable to power stations and other facilities where sulphur must be removed (Kapoor et al., 2004).

Citric acid production rates and yields are highly dependent on the type of microorganism, the type of substrate and culture conditions (Yalcin et al., 2009a; Haq et al., 2001). This study, aimed at producing citric acid from carbohydrates using a novel Aspergillus niger and its optimized strain. Authors also compared the production efficiency and growth yield of parent and mutant strains.

\section{Materials and Methods}

Fungal strain and inoculum preparation

Aspergillus niger EE-12 and its mutant strain UV-1 were used for this study. The parent strain EE-12 was 
isolated from waste water of crude oil Exploration Company located in Imo State, Nigeria. The selection of the strain EE-12 was performed with a preliminary study in which qualitative citric acid production abilities of 20 strains isolated from different sites were investigated using the dye method of Kareem et al. (2010). Of the tested strains, the highest citric acid production was obtained by $A$. niger EE-12, which was chosen for further studies. The mutant strain UV-1 was developed and screened by the treatment of the conidial suspension of the parent strain EE-12, with ultra-violet irradiation $\left(253 \mathrm{~nm}\right.$ and $\left.1.6 \times 10^{2} \mathrm{~J} / \mathrm{M}^{2} / \mathrm{S}\right)$ at a distance of $8 \mathrm{~cm}$ for 10minutes (Mazhar et al., 2003; Rao et al., 2006). The treated cells were kept in the dark for 2 hours to avoid recovery by photo reactivation. The fungi strains were stocked on Potato Dextrose Agar (PDA) slant at $4^{\circ} \mathrm{C}$ in the refrigerator. All the culture media were sterilized in the autoclave at $15 \mathrm{psi}, 121^{\circ} \mathrm{C}$ for 15 minutes except otherwise stated.

The spore suspension (inoculum) as described by Jamal et al. (2005) was employed with slight modification. Cultures of the fungi isolates grown on PDA medium in petri dishes at $32^{\circ} \mathrm{C}$ for 5 days were transferred into Erlenmeyer flask $(250 \mathrm{ml})$ containing $100 \mathrm{ml}$ of sterile distilled water. The flasks were incubated on a shaker incubator at $200 \mathrm{rpm}$ for 24 hours. Thereafter, the cultures were decanted and the supernatant was used as inoculum after measuring its strength (1.3×10 $0^{6}$ spores $\left./ \mathrm{ml}\right)$ using Haemocytometer.

\section{Fermentation technique}

The methodology and fermentation medium composition were drawn from Yigitoglu (1992), Haq et al. (2001) and Kamzolova et al. (2011). Two different fermentation media were used. The first contained $(\%$ w/v) Sucrose 15, $\mathrm{KH}_{2} \mathrm{PO}_{4} 0.1, \mathrm{MgSO}_{4} .7 \mathrm{H}_{2} \mathrm{O} 0.025$, $\mathrm{NH}_{4} \mathrm{NO}_{3} 3.25$ and $\mathrm{pH}$ 3.5. In the second medium Sucrose was replaced with Fructose. Fermentation was carried out in $1000 \mathrm{ml}$ Erlenmeyer flask containing $150 \mathrm{ml}$ of fermentation medium inoculated with $2 \%$ $(\mathrm{v} / \mathrm{v})(3 \mathrm{ml})$ spore suspension in sterile distilled water. Flasks were incubated in the rotary incubator shaker (200rpm) at room temperature $\left(28 \pm 2^{0} \mathrm{C}\right)$ for 144 hours. All the experiments were run in triplicates. Sample aliquots were withdrawn at intervals of 12 hours and used for Citric acid production, sugar (Fructose or Sucrose) consumption and Biomass estimations.

\section{Assay methods}

Samples were taken from the fermentation medium and centrifuged at $5000 \mathrm{rpm}$ for 20 minutes at room temperature. The clear supernatant was used for estimation. The amount of citric acid in the sample was estimated spectrophotometrically, using PyridineAcetic anhydride method (Marrier and Boulet, 1958;
Kishore et al., 2008). Sucrose in the fermentation sample was estimated by Dinitrosalicylic acid (DNS) method described by Kishore et al. (2008). Fructose in the supernatant was measured by the adopted Seliwanoff's method described by Ferreira et al. (2010). For biomass estimation, the modified methods of Alben and Erkmen (2004) and Kishore et al. (2008) was used. The sample was filtered through a preweighted whatman filter paper. After filtration, it was dried in an oven at $105^{\circ} \mathrm{C}$ to constant mass, cooled in a desiccator and thereafter the final weight was measured. The difference between initial and final weight was the biomass.

\section{Kinetic analysis of cell growth and citric acid production}

Kinetic parameters of batch fermentation process were determined, adopting the procedures reported by Mazhar et al. (2003) and Yalcin et al. (2009a\&b). Product and growth yield coefficients $\left(\mathrm{Y}_{\mathrm{CA} / \mathrm{S}}, \mathrm{Y}_{\mathrm{CA} / \mathrm{F}}\right.$, $\left.\mathrm{Y}_{\mathrm{CA} / \mathrm{X}}, \mathrm{Y}_{\mathrm{X} / \mathrm{S}}, \mathrm{Y}_{\mathrm{X} / \mathrm{F}}\right)$ and volumetric rates $\left(\mathrm{Q}_{\mathrm{F}}, \mathrm{Q}_{\mathrm{S}}, \mathrm{Q}_{\mathrm{CA}}\right.$, $\mathrm{QX}_{\mathrm{X}}$ ) were determined.

Parameters: $\mathrm{Y}_{\mathrm{CA} / \mathrm{S}}=\mathrm{Y}_{\mathrm{CA} / \mathrm{F}}=\mathrm{g}$ citric acid produced $/ \mathrm{g}$ substrate consumed, $\mathrm{Y}_{\mathrm{CA} / \mathrm{X}}=\mathrm{g}$ citric acid produced $/ \mathrm{g}$ cell formed, $Y_{X / S}=Y_{X / F}=g$ cell formed $/ g$ substrate consumed, $\mathrm{Q}_{\mathrm{F}}=\mathrm{Q}_{\mathrm{S}}=\mathrm{g}$ substrate consumed $/ \mathrm{L} / \mathrm{h}, \mathrm{Q}_{\mathrm{CA}}$ $=\mathrm{g}$ citric acid produced $/ \mathrm{L} / \mathrm{h}, \mathrm{Q}_{\mathrm{X}}=\mathrm{g}$ cell formed $/ \mathrm{L} /$ h.

Where: $\mathrm{CA}=$ Citric acid, $\mathrm{X}=$ Biomass, $\mathrm{S}=$ Sucrose (substrate), $\mathrm{F}=$ Fructose (substrate).

\section{Statistical analysis}

The results indicate the mean \pm standard deviation of three separate trials where three independent cultures were used in the experimental design. The findings were statistically compared using the student's t-test (SPSS - 16.0 and Microsoft Excel 2007).

\section{Result and Discussion}

The ability of a novel $A$. niger EE-12 and its ultra violet radiation improved strain, $A$. niger UV-1 to produce citric acid from sugar based mineral salt media in shake flasks were studied. Citric acid production was carried out in a batch submerged fermentation at $30^{\circ} \mathrm{C}$ and initial $\mathrm{pH} 3.5$ for 144 hours with $15 \%$ initial sugar concentration in a $250 \mathrm{ml}$ shake flasks at $200 \mathrm{rpm}$. Advantages of submerged technique include the possible use of wide range of substrates and better control of fermentation. In addition, it is less labour intensive, gives a higher production rate and uses less space (Pazouki et al., 2000). Nevertheless, the optimum time of incubation for maximum citric acid production varies both with the organism and fermentation conditions (Kubicek, 1998 and Ali et al., 2002). Mineral salt medium is a synthetic one that 
normally contains a carbon source, a nitrogen source, phosphorus and magnesium source. The concentrations of all these elements have a profound effect on the yield of citric acid (Ali et al., 2001, Haq et al., 2001). Thus, the optimal citric acid production depends on the type of fermentation media used (Singh et al., 1998).

During the fermentation period, variations in citric acid concentration, sugar consumed (residual) and dry biomass of the strains were determined at specific time intervals for both of the substrates (Sucrose and fructose) as shown in figures 1 and 2. Overall, citric acid production started after a lag phase of about 12 24 hours and reached maximum within and at the onset of stationary phase. This is in perfect alliance with the report of Rajoka et al. (1998). An inverse relationship between citric acid production and the consumption of sugar was observed and this is in agreement with the report of Kareem et al. (2010). Also, the initial sugar concentration decreased throughout the fermentation period for both strain on sucrose and fructose salt media. Citric acid production was significantly different $(p<0.05)$ in fig. 1 after 144 hours while it was not in fig. 2. Strain UV-1 had the highest sugar consumption of $134.2 \pm 0.2 \mathrm{~g} / 1$ and $94.0 \pm 0.8 \mathrm{~g} / 1$ on fructose and sucrose salt media respectively after 144 hours while the parent strain had $91.0 \pm 0.8 \mathrm{~g} / 1$ and $72.1 \pm 0.2 \mathrm{~g} / 1$ respectively. Though there was a steady increase in dry biomass throughout the fermentation period, strain UV-1 equally had the highest biomass formation of $15.0 \pm 0.1 \mathrm{~g} / 1$ and $12 . \pm 0.1 \mathrm{~g} / 1$ on sucrose and fructose salt media respectively. This indicated that the cells were still viable. Thus, it suggests a link between storage of carbon, biomass formation and production of citric acid (Alben and Erkem, 2004). Kishore et al. (2008) reported a similar result in their work. Comparatively, biomass formation by strain UV-1 and its parent EE-12 strain on sucrose and fructose salt media were significantly not different (Table 2).

Citric acid production by $A$. niger EE-12 (parent) and its improved UV-1 strain on sucrose salt medium were significantly different $(\mathrm{p}<0.05)$ while they had no significant difference $(p>0.05)$ on fructose salt medium. The citric acid produced by strain UV-1 was significantly higher $(\mathrm{p}<0.05)$ than the level produced by EE-12 after 144 hours of growth (Table 1) on sucrose salt medium. The improved strain produced 1.14 fold higher citric acid level than its parent strain after 120 and 144 hours of growth on sucrose salt medium, with the difference in citric acid production being statistically significant $(\mathrm{p}<0.05)$. Furthermore, citric acid productions by both strains on sucrose salt medium were significantly higher $(p<0.05)$ than the concentration produced on fructose salt medium. The parent strain produced 1.6 fold higher citric acid on sucrose salt medium than on fructose salt media while strain UV-1 produced 1.9 fold higher citric acid on sucrose salt medium against fructose salt medium. Strain UV-1 gave 13\% improvement for citric acid production on sucrose salt medium. Mazhar et al. (2003) carried out mutational studies using $A$. niger and reported $15-22 \%$ improvement in citric acid production. So, the results obtained with our UV irradiated fungi isolate gave a lower improvement. This could be attributed to the fact that Mazhar et al. (2003) reported their best results after a combination of strain and process optimization. However, UV-irradiated DNA is unstable and recovers due to photo reactivation (Haq et al., 2001).

The utilization of the substrate in cells concerns the consumption of substrate for growth, maintenance and product formation, thus its kinetics was considered. Different kinetic parameters such as product and growth yield coefficients $\left(\mathrm{Y}_{\mathrm{CA} / \mathrm{S}}, \mathrm{Y}_{\mathrm{CA} / \mathrm{F}}, \mathrm{Y}_{\mathrm{CA} / \mathrm{X}}, \mathrm{Y}_{\mathrm{X} / \mathrm{S}}\right.$, $\left.\mathrm{Y}_{\mathrm{X} / \mathrm{F}}\right)$ and volumetric rates $\left(\mathrm{Q}_{\mathrm{F}}, \mathrm{Q}_{\mathrm{S}}, \mathrm{Q}_{\mathrm{CA}}, \mathrm{Q}_{\mathrm{X}}\right)$ were studied and compared for each of the test isolates based on the media used (figures $3-6$ ). Comparatively, the values for product and growth yield coefficients of the parent strain EE-12 and its improved UV-1 strain on sucrose salt medium were significantly higher than on fructose salt medium $(p<0.05)$. The above result could be as a result of higher preference for glucose component of sucrose by A. niger (Waites et al., 2001). Also, volumetric rate of citric acid production on sucrose salt medium are significantly higher than on fructose salt medium $(\mathrm{p}<0.05)$. In figure 3 , the volumetric rate of substrate consumption $\left(\mathrm{Q}_{\mathrm{F}}\right.$ and $\left.\mathrm{Q}_{\mathrm{S}}\right)$ were not statistically different after 144 hours but were significantly different $(\mathrm{p}<0.05)$ after 24 hours. This is the early exponential phase thus there is a high need for carbon source thereby resulting to rapid breakdown of sucrose into readily utilizable glucose or fructose. Equally, at the prevailing $\mathrm{pH}$ of the fermentation medium acid hydrolysis of sucrose could have contributed to the result. The volumetric rate of citric acid production $\left(\mathrm{Q}_{\mathrm{CA}}\right)$ and the mass yield $\left(\mathrm{Y}_{\mathrm{CA}}\right)$ of $A$. niger UV-1 and its parent strain EE-12 are comparable to those reported in the literature for citrate producing strains (Rajoka et al., 1998 and Mazhar et al., 2003). Biomass yield coefficients $\left(\mathrm{Y}_{\mathrm{X} / \mathrm{S}}, \mathrm{Y}_{\mathrm{X} / \mathrm{F}}\right)$ and product yield coefficients $\left(\mathrm{Y}_{\mathrm{CA} / \mathrm{S}}, \mathrm{Y}_{\mathrm{CA} / \mathrm{F}}\right)$; an index of the efficiency of conversion of a substrate into biomass and product respectively, as shown in figures $5 \& 6$ are considerably moderate. However, organisms may exhibit different yield coefficients for the same substrate, due primarily to the pathway by which the compound is metabolized (Waites et al., 2001). 


\section{Conclusion}

This work confirmed the growth and citric acid production characteristics of two A. niger strains (EE12 and UV-1) using mineral salt media containing sucrose or fructose as its carbon source. This showed the difference in citric acid production capabilities of the strains in these media, revealing that sucrose is a better carbon source for citric acid production. Natural sources of this sugar are therefore promising substrates for citric acid production processes. Citric acid production of the improved UV-1 strain was higher than that of its parent EE-12 strain. The data for kinetic parameters give an idea about optimizing the culture conditions in a possible scale-up of citric acid production process. Undoubtedly, strain optimization and selection are important stages for citric acid production process; thus finding new efficient and improved strains for an industry is a veritable innovation. A domestic Nigerian strain with minimal optimization strategies was confirmed to be efficient for citric acid production. This can be geared towards local content development. The authors strongly suggest further optimization research on these fungi strains.
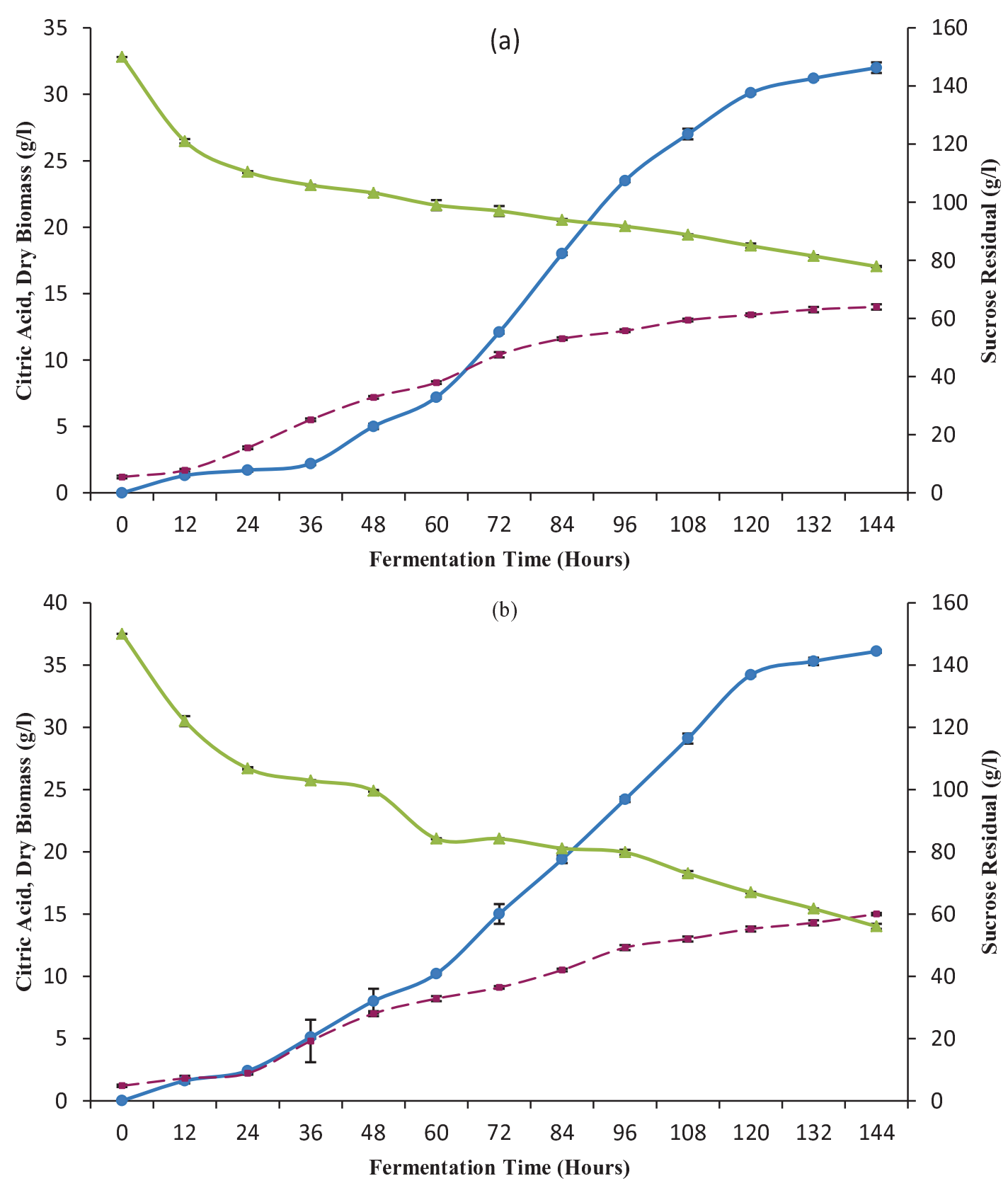

$\longrightarrow$ Citric acid (g/l) $\quad--$ Dry Biomass $(\mathrm{g} / \mathrm{l}) \quad \longrightarrow$ Sucrose residual (g/l)

Fig. 1: Time course of Dry biomass, Sucrose consumption (Residual) and Citric acid production by $A$. niger EE-12 (a) and $A$. niger UV-1 (b) grown on Sucrose Salt medium. Y error bars indicate the standard deviation of the triplicates. 

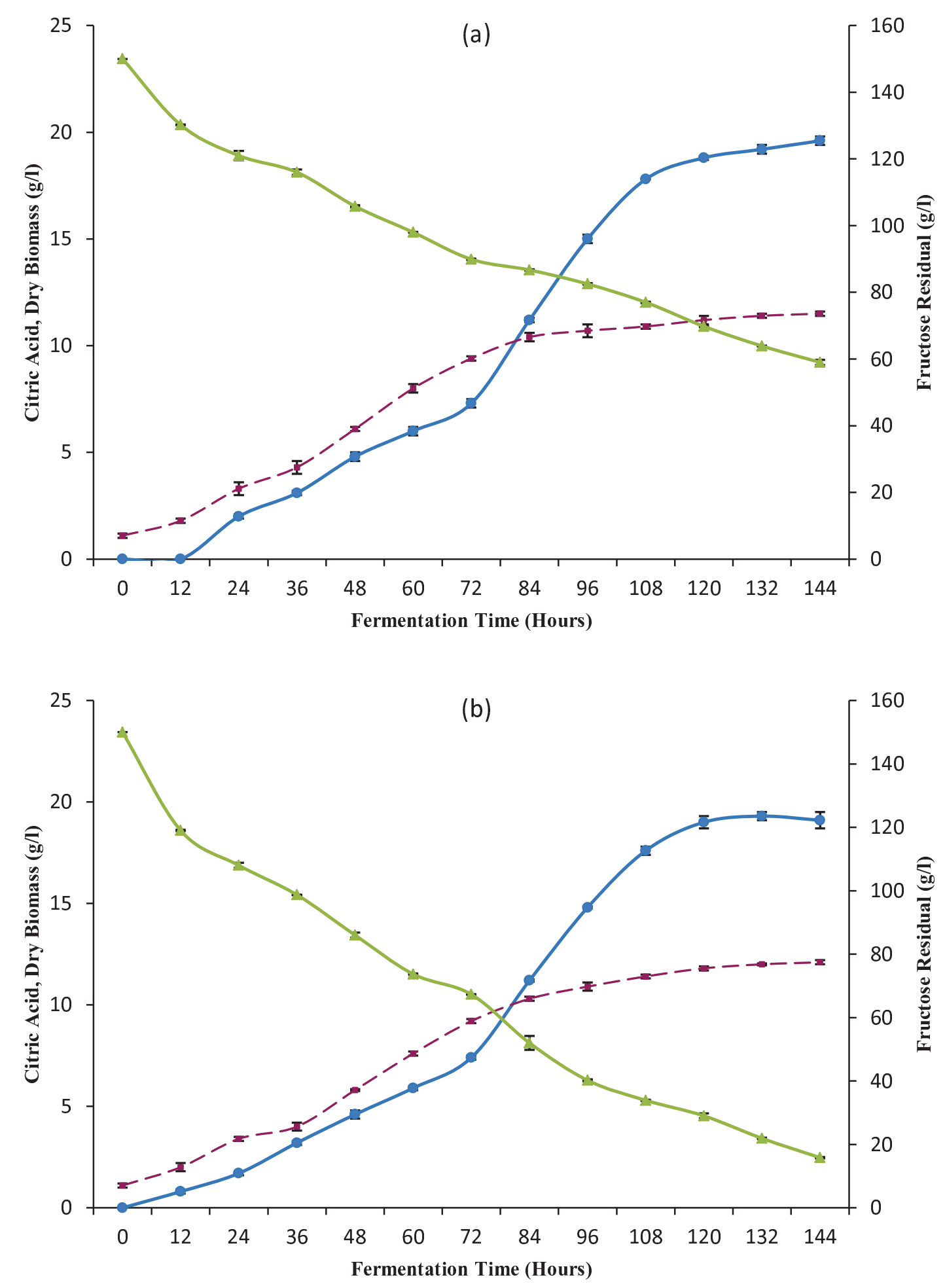

$\longrightarrow$ Citric acid (g/l) $\quad--$ Dry Biomass $(g / l) \quad \longrightarrow$ Fructose residual $(\mathrm{g} / \mathrm{l})$

Fig. 2: Time course of Dry biomass, Fructose consumption (Residual) and Citric acid production by A. niger EE-12 (a) and A. niger UV-1 (b) grown on Fructose Salt medium. Y error bars indicate the standard deviation of the triplicates. 

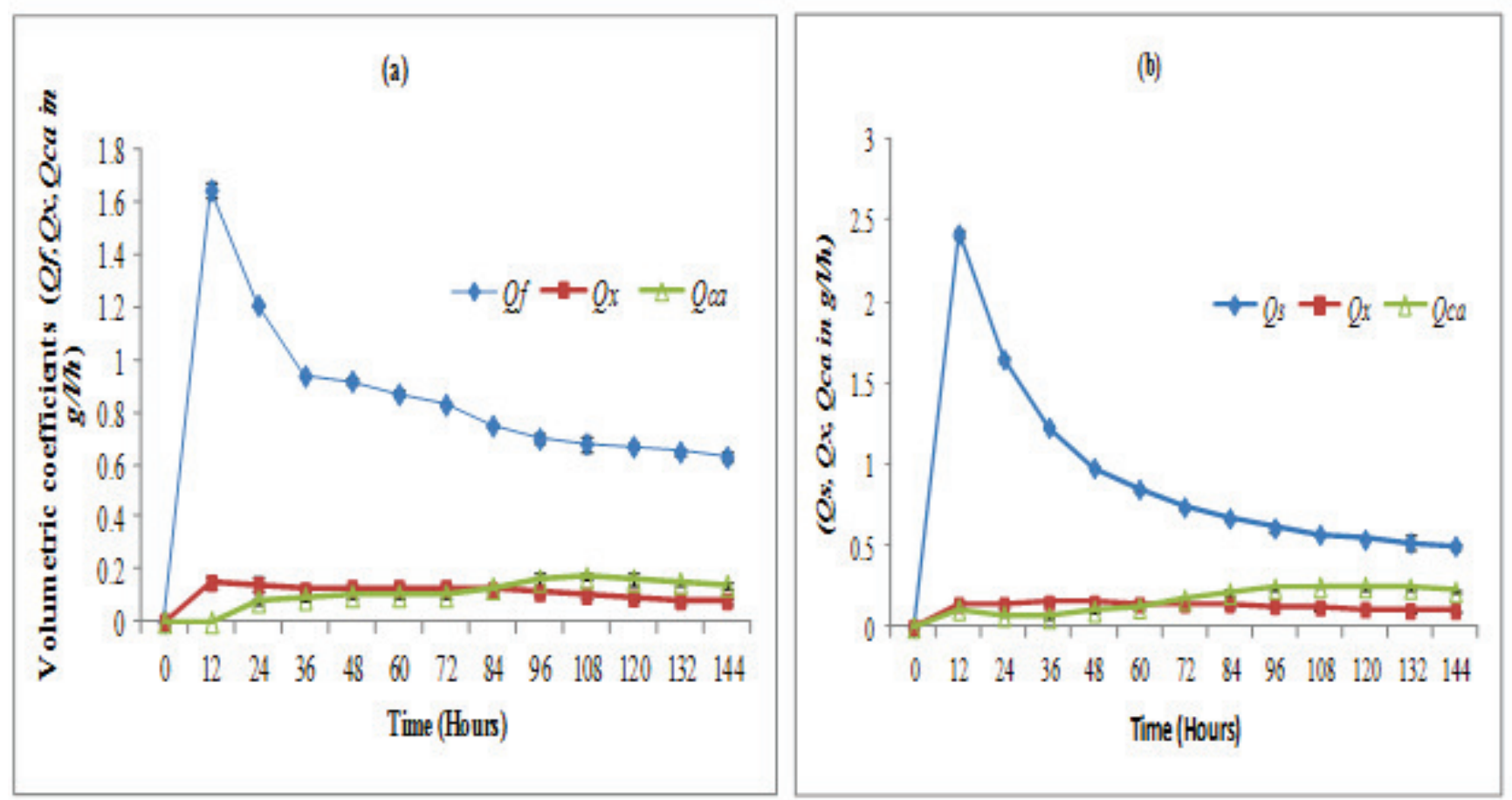

Fig. 3: Comparison of volumetric coefficients for citric acid production by $A$ niger EE-12 on Fructose salt medium (a) and Sucrose salt medium (b). Values for volumetric rate of substrate consumption ( $\mathrm{Q}_{\text {Fand }} \mathrm{Q}_{2}$ ) are not statistically different $(\mathrm{P}>0.05)$ while values for volumetric rate of biomass formation and citric acid production $\left(\mathrm{Q}_{\mathrm{X}}\right.$ and $\left.\mathrm{Q}_{\mathrm{e}}\right)$ are significantly different $(\mathrm{P}>0.05)$ respectively.
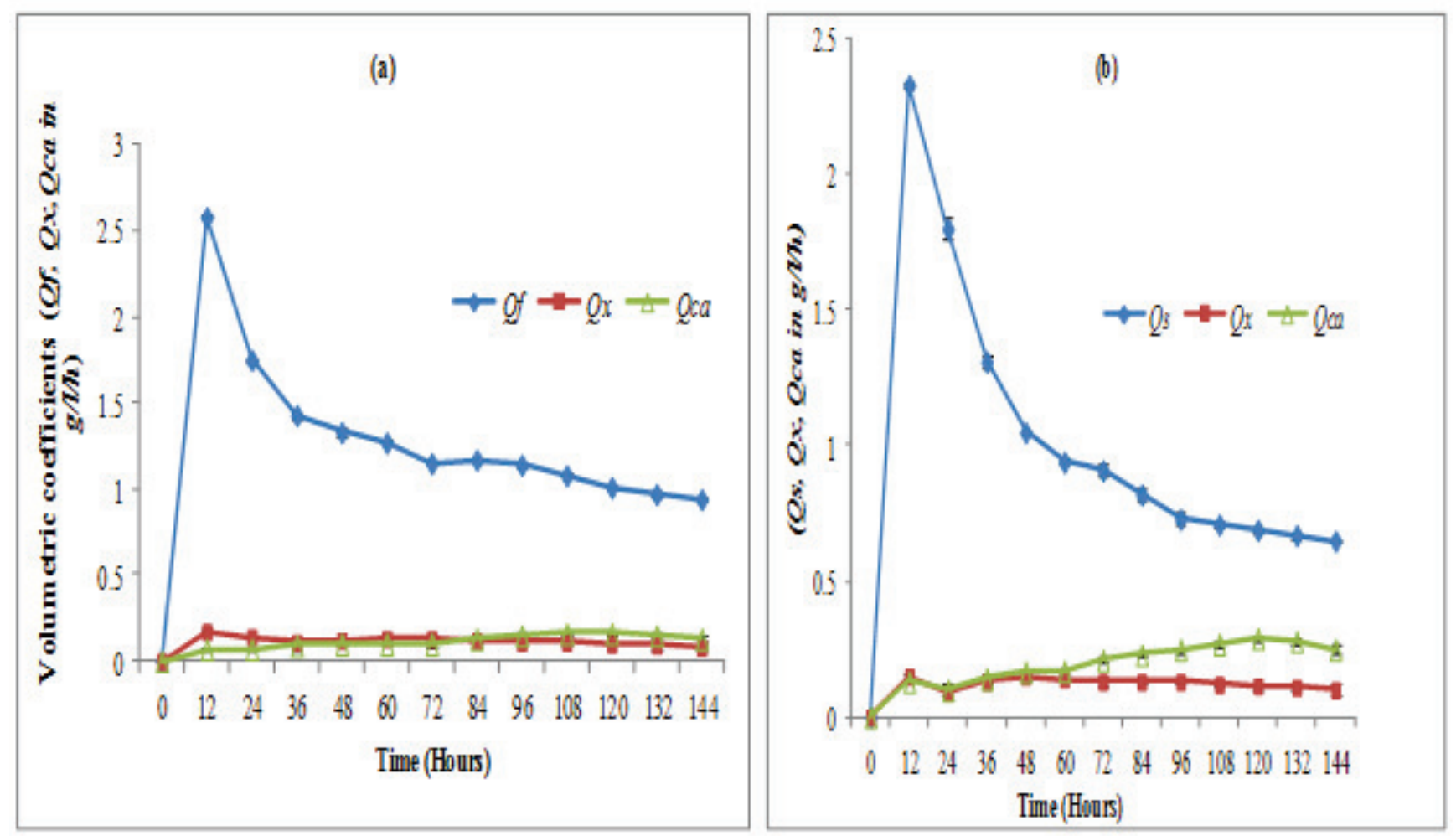

Fig. 4: Comparison of volumetric coefficients for citric acid production by $A$ niger UV-1 on Fructose salt media (a) and Sucrose salt media (b). Values for volumetric rate of substrate consumption $\left(\mathrm{Q}_{\mathrm{F}}\right.$ and $\left.\mathrm{Q}_{2}\right)$ and citric acid production $\left(\mathrm{Q}_{e N}\right)$ are significantly different $(\mathrm{P}<0.05)$ while values for volumetric rate of biomass formation $\left(\mathrm{QW}_{\mathrm{W}}\right)$ are not statistically different $(\mathrm{P}>0.05)$. 

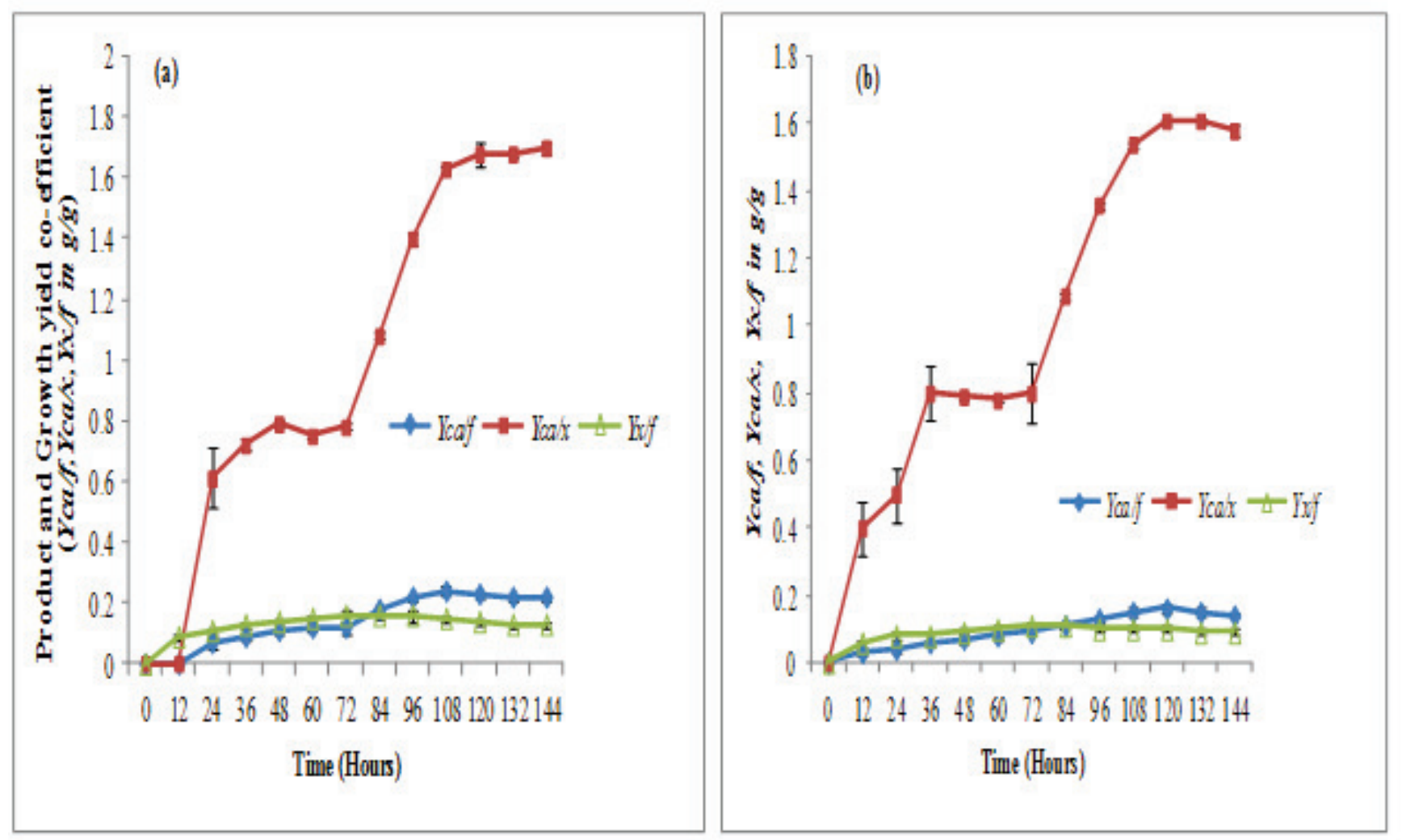

Fig. 5: Comparison of product and growth yield coefficients for citric acid production by $A$ niger EE-12 (a) and $A$ niger UV-1 (b) on Fructose salt medium. The values for $Y c a / f$ and $Y x / f$ are significantly different $(p<0.05)$ respectively while values for $Y c a / x$ are not significant $(p>0.05)$.
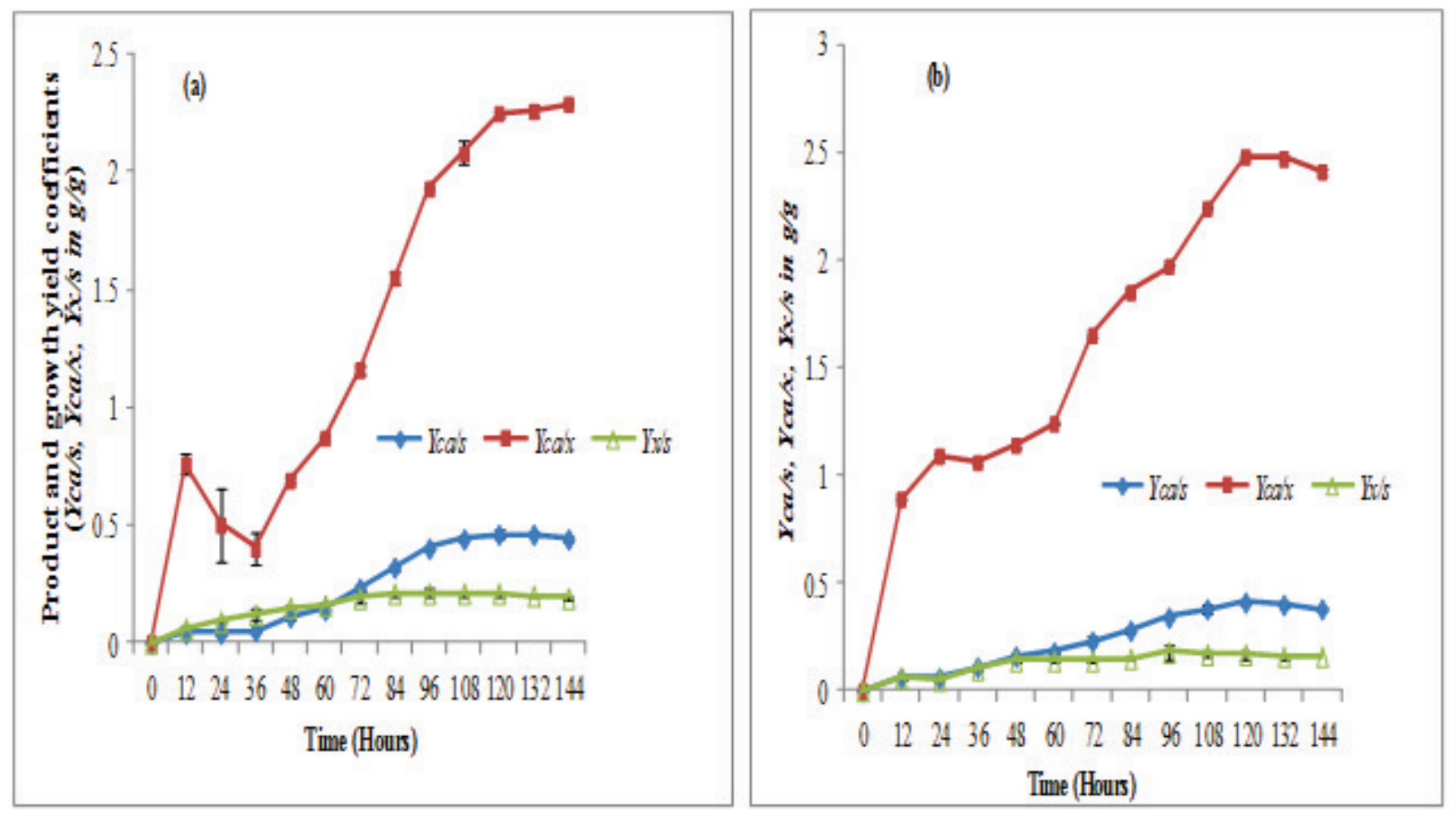

Fig. 6: Comparison of product and growth yield coefficients for citric acid production by $A$ niger EE-12 (a) and $A$ niger UV-1 (b) on Sucrose salt medium. The values for $Y c a / x$ and $Y x / s$ are significant $(\mathrm{p}<0.05)$ respectively while values for $Y c a / s$ are not significant $(p>0.05)$. 
VE Anyanwu and PO Okerentugba (2013). Int J Appl Sci Biotechnol, Vol. 1(3): 145-153

Table 1: Comparison of citric acid production between A. niger EE-12 and its improved (UV-1) strain after growth on two different fermentation media.

\begin{tabular}{|c|c|c|c|c|}
\hline \multirow{3}{*}{$\begin{array}{l}\text { Fermentation } \\
\text { time(h) }\end{array}$} & \multicolumn{4}{|c|}{ Citric acid concentration $\left(\mathrm{gL}^{-1}\right)$} \\
\hline & \multicolumn{2}{|c|}{ Sucrose Salt Medium } & \multicolumn{2}{|c|}{ Fructose salt medium } \\
\hline & EE-12 & $\mathrm{UV}-1$ & EE-12 & UV-1 \\
\hline 0 & $0.0 \pm 0.0^{\mathrm{a}}$ & $0.0 \pm 0.0^{\mathrm{a}}$ & $0.0 \pm 0.0^{\mathrm{a}}$ & $0.0 \pm 0.0^{\mathrm{a}}$ \\
\hline 24 & $1.7 \pm 0.1^{\mathrm{a}}$ & $2.4 \pm 0.1^{\mathrm{a}}$ & $2.0 \pm 0.1^{\mathrm{a}}$ & $1.7 \pm 0.1^{\mathrm{a}}$ \\
\hline 48 & $5.0 \pm 0.2^{\mathrm{a}}$ & $8.0 \pm 1.0^{\mathrm{b}}$ & $4.8 \pm 0.2^{\mathrm{a}}$ & $4.6 \pm 0.2^{\mathrm{a}}$ \\
\hline 72 & $12.1 \pm 0.1^{\mathrm{a}}$ & $15.0 \pm 0.8^{\mathrm{b}}$ & $7.3 \pm 0.2^{\mathrm{a}}$ & $7.4 \pm 0.1^{\mathrm{a}}$ \\
\hline 96 & $23.5 \pm 0.1^{\mathrm{a}}$ & $24.2 \pm 0.2^{\mathrm{a}}$ & $15.0 \pm 0.2^{\mathrm{a}}$ & $14.8 \pm 0.05^{\mathrm{a}}$ \\
\hline 120 & $30.1 \pm 0.1^{\mathrm{a}}$ & $34.2 \pm 0.1^{\mathrm{b}}$ & $18.8 \pm 0.1^{\mathrm{a}}$ & $19.0 \pm 0.3^{\mathrm{a}}$ \\
\hline 144 & $32.0 \pm 0.4^{\mathrm{a}}$ & $36.1 \pm 0.1^{\mathrm{b}}$ & $19.6 \pm 0.2^{\mathrm{a}}$ & $19.1 \pm 0.4^{\mathrm{a}}$ \\
\hline
\end{tabular}

Concentrations are mean of three independent set-up \pm standard deviation, subscripts in the same row of data that have different letters are statistically different at $\mathrm{p}<0.05$ using student's t-test.

Table 2: Comparison of biomass formation by A. niger UV-1 (improved) and its parent (EE-12) strain grown on two different fermentation (sugar) media.

\begin{tabular}{|c|c|c|c|c|}
\hline \multirow[b]{3}{*}{ Fermentation time(h) } & \multicolumn{4}{|c|}{ Dry biomass concentration $\left(\mathrm{gL}^{-1}\right)$} \\
\hline & \multicolumn{2}{|c|}{ Sucrose Salt Medium } & \multicolumn{2}{|c|}{ Fructose salt medium } \\
\hline & EE-12 & UV-1 & $\mathrm{EE}-12$ & UV-1 \\
\hline 0 & $1.2 \pm 0.1^{\mathrm{a}}$ & $1.2 \pm 0.1^{\mathrm{a}}$ & $1.1 \pm 0.1^{\mathrm{a}}$ & $1.1 \pm 0.1^{\mathrm{a}}$ \\
\hline 24 & $3.4 \pm 0.1^{\mathrm{a}}$ & $2.2 \pm 0.1^{\mathrm{a}}$ & $3.3 \pm 0.3^{\mathrm{a}}$ & $3.4 \pm 0.1^{\mathrm{a}}$ \\
\hline 48 & $7.2 \pm 0.1^{\mathrm{a}}$ & $7.0 \pm 0.2^{\mathrm{a}}$ & $6.1 \pm 0.1^{\mathrm{a}}$ & $5.8 \pm 0.05^{\mathrm{a}}$ \\
\hline 72 & $10.4 \pm 0.2^{\mathrm{a}}$ & $9.1 \pm 0.1^{\mathrm{a}}$ & $9.4 \pm 0.1^{\mathrm{a}}$ & $9.2 \pm 0.1^{\mathrm{a}}$ \\
\hline 96 & $12.2 \pm 0.1^{\mathrm{a}}$ & $12.3 \pm 0.2^{\mathrm{a}}$ & $10.7 \pm 0.3^{\mathrm{a}}$ & $10.9 \pm 0.2^{\mathrm{a}}$ \\
\hline 120 & $13.4 \pm 0.1^{\mathrm{a}}$ & $13.8 \pm 0.2^{\mathrm{a}}$ & $11.2 \pm 0.2^{\mathrm{a}}$ & $11.8 \pm 0.1^{\mathrm{a}}$ \\
\hline 144 & $14.0 \pm 0.2^{\mathrm{a}}$ & $15.0 \pm 0.1^{\mathrm{a}}$ & $11.5 \pm 0.1^{\mathrm{a}}$ & $12.1 \pm 0.1^{\mathrm{a}}$ \\
\hline
\end{tabular}

Concentrations are mean of three independent set-up \pm standard deviation, subscripts in the same row of data that have a common letter are not statistically different at $\mathrm{p}>0.05$ using student's t-test.

\section{Reference}

Alam MZ, Fakhru'l-Razi A and Molla AH (2003) Optimization of Liquid State Bioconversion Process for Microbial Treatment of Domestic Wastewater Sludge. Journal of Environmental Engineering \& Science 2: 299-306.

Alben E and Erkmen O (2004) Production of Citric acid from a New Substrate, Undersized Semolina, by Aspergillus niger. Food Technology and Biotechnoogy 42(1): 1922.

Ali S, Haq I and Iqbal J (2001) Effect of Vegetative Inoculum on Submerged Citric acid Fermentation by Aspergillus niger using Stirred Fermentor. Biologia 46(2): 54-57

Ali S, Haq I, Qadeer MA and Iqbal J (2002a) Production of Citric acid by Aspergillus niger Using Cane Molasses in a Stirred Fermentor. Electronic Journal of Biotechnology 5(3): 258-271.

Ali S, Haq I and Iqbal J (2002b) Citric acid Fermentation by a UV Treated Mutant of Aspergillus niger. Pakistan Journal of Botany 34(2): 125-128

Casida LE (1968) Industrial Microbiology. New Age International Publishers, New Delhi. 402-403.

Crueger W and Crueger A (1984) Biotechnology: A Textbook of Industrial Microbiology. R.R. Donnelley and Co. Science Tech., Inc., USA. 112.
Ferreira NR, Sarquis MIM, Alves CN and Santos AS (2010) Biotransformation of Sucrose into 5-hydroxy-2hydroxymethyl- $\gamma$-pirone by Aspergillus flavus. An. Acad. Bras. Cienc. 82(3): 569 - 576.

Haq I, Ali S, Ashraf H, Butt WA, Qadeer MA, Shafiq K and Iqbal J (2001) Effect of Mineral Nutrient on the Production of Citric acid by Aspergillus niger UV-6, Using Sucrose Salt Media. Pakistan Journal of Botany 33: $535-540$

Jamal P, Alam MZ, Ramlan M, Salleh M and Nadzir MM (2005) Screening of Aspergillus for Citric acid Production from Palm Oil Mill Effluent. Biotechnology 4(4): 275-278.

Kamzolova SV, Fatykhova AR, Dedyukhina EG, Anastassiadis SA, Golovchenko NP and Morgunov IG (2011) Citric acid Production by Yeast Grown on Glycerol-containing Waste from Biodiesel Industry. Food Technology and Biotechnology 49(1): 65-74.

Kareem SO, Akpan I and Alebiowu OO (2010) Production of Citric acid by Aspergillus niger using Pineapple Waste. Malaysian Journal of Microbiology 6(2): 161-165

Kapoor KK, Chaudhary K and Tauro P (2004) Citric acid. In: Reed G (Ed.) Prescott and Dunn's Industrial Microbiology, $4^{\text {th }}$ Edn. Chapter 8. CBS Publishers Ltd, New Delhi, India. 709-739. 
VE Anyanwu and PO Okerentugba (2013). Int J Appl Sci Biotechnol, Vol. 1(3): 145-153

Kishore KA, Kumar MP, Krishna VR and Reddy GV (2008) Optimization of Process Variables of Citric acid Production using Aspergillus niger in a Batch Fermentor. Engineering Letters 16(4): 17 - 22.

Kubicek CP (1998) The Role of Sugar Uptake and Channelling for Citric acid Accumulation by Aspergillus niger. Food Technology and Biotechnology 36(3): $173-175$.

Magnuson JK and Lasure LL (2004) Organic Acid Production by Filamentous Fungi. In: Lange $\mathrm{J}$ and Lange L (Eds.). Advance in Fungal Biotechnology for Industry, Agriculture and Medicine. Kluwer Academic/Plenum publishers, Wales. 307-319.

Marrier JR and Boulet M (1958) Direct Determination of Citric Acid in Milk with an Improved Pyridine Acetic Anhydride method. Journal of Diary Sciences 41: 1683

Mazhar R, Rehman A, Ali S and Haq I (2003) Kinetics of Citric acid Over-Production by an Aspergillus niger Mutant RABt-10. Pakistan Journal of Botany 35(4): $547-552$.

Papagianni M (2007) Advance in Citric acid Fermentation by Aspergillus niger. Biotechnology Advances 25: 244263.

Pazouki M, Felse PA, Sinha I and Panda T (2000) Comparative Study on Citric acid Production by Aspergillus niger and Candida lipolytica using Molasses and Glucose. Bioprocess Engineering 22: 353 -361 .

Rajoka MI, Ahmad MN, Shahid R, Latiff F and Parvez S (1998) Citric acid Production from Sugar Cane Molasses by Cultures of Aspergillus niger. Biologia 44(1): $241-253$.
Rao RS, Jyothi CP, Prakasham RS, Rao CS, Sarma NP and Rao LV (2006) Strain Improvement of Candida tropicalis for the Production of Xylitol: Biochemical and Physiological Characterization of Wild-type and Mutant Strain CT-OMV5. Journal of Microbiology 44(1): 113-120.

Singh SP, Chaurasia PK, Prasad R and Raujun A (1998) Microbial Production of Citric acid Exposed to some Metallic Micro Minerals. Oriental Journal of Chemistry 14(3): 439 - 442.

Waites MJ, Morgan NL, Rockey JS and Higton G (2001) Industrial Microbiology; An Introduction. Blackwell Publishing, Oxford. 155-158.

Yalcin SK, Bozdemir MT and Ozbas ZY (2009a) A Comparative Study of the Effects of Glycerol and Mannitol on Citric Acid Production by Two Yarrowia lipolytica Strains. Romanian Biotechnology Letters 14(6): 4870 - 4881.

Yalcin SK, Bozdemir MT and Ozbas ZY (2009b) A Comparative Study on Citric acid Production Kinetics of two Yarrowia lipolytica Strains in two Different Media. Indian Journal of Biotechnology 8: 408-417.

Yalcin SK, Bozdemir MT and Ozbas ZY (2010) Citric acid Production by Yeast: Fermentation Conditions, Process Optimization and Strain Improvement. In: MendezVilas A (Ed.) Current Research, Technology and Education Topics in Applied Microbiology and Microbial Biotechnology. Formatex, Turkey. 13741382.

Yigitoglu M (1992) Production of Citric acid by Fungi. Journal of Islamic Academy of Science 5(2): 100-106. 